\title{
SOBRE JOSÉ GAOS Y EL ABSURDO DE ENSEÑAR FILOSOFIA ${ }^{*}$
}

Josep Martinez Bisbal

\begin{abstract}
One of the conclusions that Jose Gaos draws from his philosophy and expresses radically in his De la filosofia (1960) is the absurdity of teaching philosophy. In the present paper, his analysis is studied comparing that work with his Confesiones Profesionales (1953), emphasising the different vital situation in which both works were written and the tension between Gaos the professor and Gaos the philosopher that runs through them.
\end{abstract}

Keyworks: Philosophy; Teaching of Phisosophy; Philosophy of Philosophy.

\section{RESUMO}

Uma das conclusões a que Jose Gaos chegou em sua filosofia e que foi expressa radicalmente em sua obra De la filosofia (1960) é o absurdo de se ensinar filosofia. Este artigo oferece uma análise desta afirmação a partir do estudo comparativo da obra citada com as Confis-

* Este trabajo ha sido realizado dentro del proyecto de investigación "Filosofía en castellano 1945-1970" (BFF2002-01558) y se leyó en las"Jornadas internacionales sobre la obra filosófica de José Gaos" celebradas en la Universitat de València el 10, 11 y 12 de mayo de 2004. El filósofo José Gaos (España 1900-México 1969) se formó en la llamada Escuela de Madrid con M. García Morente y sobre todo con J. Ortega y Gasset de quien fue discípulo predilecto. Rector de la Universidad de Madrid durante la guerra de España, a la derrota de la República se exilió en México donde vivió el resto de su vida y realizó la mayor parte de su obra.

** Doutor em Filosofia e Professor na Universitat de València. 
sões Profissionais (1953), enfatizando a diferença essencial de ambos os trabalhos e a tensão entre as orientações do Gaos professor e do Gaos filósofo.

Palavras-chave: Filosofia, Ensino de Filosofia, Filosofia da Filosofia.

"Pero parece que el hombre tiene que reconocer que no puede dar razón de la existencia de un ente como él en lo existente (...) de la existencia de un ente que vive, ama y odia bienes y males y concibe la nada y un Bien infinito".

De la Filosofía, p. 393.

En las páginas finales de De la Filosofía, el curso leído el 1960, en la última lección titulada "Autobiografía y autocrítica del curso", como última conclusión coherente con su filosofía, Gaos afirma:

"Por eso no hay un diálogo filosófico - a fondo: filosóficamente, a fondo no puede haber más que monólogo en soledad. No es mi culpa, ni por ende, mío el remedio - imposible, de que esto reduzca al absurdo los congresos de filosofía - y la misma enseñanza de la Filosofía".1

Esta rotunda afirmación sobre lo absurdo de pretender enseñar filosofía no puede menos que inquietar al lector si éste, como es el caso, ejerce como profesor de filosofía y, más aún, si está leyéndole para entender su concepción de la enseñanza de la filosofía y participar con ello en unas jornadas de diálogo filosofico sobre su obra. Parece que sin disentir de ella no se puede seguir, con lo que, como quiere Gaos, no haremos más que darle la razón pues sólo espera del otro el inevitable disentimiento de su filosofía.

1 José Gaos: De la Filosofia, Obras Completas, vol. XII, México, UNAM, 1982, p. 427. La cursiva es deI original, y el guión que la precede, en la peculiar notación de Gaos, indica un énfasis especial que había de manifestarse en el momento de su lectura en clase. 
De hecho, ni el mismo Gaos puede seguir sin disentir de sí mismo pues este nihilismo "hace a la Filosofía y a la enseñanza de ésta objeto de un atentado explosivo que debiera ser denunciado a las autoridades de esta Casa y penado 'capitalmente' por ellas". Sigue por ello con una hemipanilodia, una semi-retractación sobre la que luego volveré, que presenta en breves y condensadas líneas una síntesis de su filosofía "bajo otro punto de vista" que el de su subjetividad - que cabe interpretar como el público y transmisible - , es decir, anota aquello que cree añadir a la historia textual de la filosofía. En realidad, el problema de la afirmación que considera absurda la enseñanza de la filosofía no es tanto o sólo el que pueda plantear a su lector, como el que plantea al mismo Gaos que, a poco más de una página de la afirmación, cierra la lección - que cree que será la última de su vida como profesor - y con ella el curso de Filosofía de la filosofía y el libro con la proclamación de que "no ha sido ni querido ser otra cosa que profesor de Filosofía a lo largo de los treinta y siete años bien cumplidos en que lo ha sido", con lo que no hace más que reafirmar la declaración, si cabe aún más enfática, formulada en la primera lección y con la que justifica la cuestión crucial de la forma de expresión que adopta para su filosofía:

"Yo he sido y soy esencialmente, auténticamente, un profesor más que ninguna otra cosa que también haya sido o sea, o pueda o pudiera haber sido o ser, intelectualmente. Me ha parecido, pues, que a la expresión o exposición con la mayor probabilidad definitiva del resultado de los esfuerzos hechos a lo largo de la vida para cumplir con el deber contraido al hacer profesión de lo que he sido y soy esencialmente, debía darle la forma más propia de los esfuerzos propios, a su vez, de un profesor: la de un curso". ${ }^{2}$

En efecto, como sabemos, constantemente por lo menos desde los años cincuenta, se define como profesor de filosofía, como alguien que ha hecho de ello profesión de fe y de vida y que, como muestra

2 De la Filosofia, op. cit., pp. 8-9. 
su obra - casi toda ella textos de sus cursos impartidos de filosofía - y reconocen sus discípulos, la ejerció con una profunda seriedad y un elevado sentido del deber y la responsabilidad ${ }^{3}$. Vida, profesión y obra filosófica, inextricables en Gaos, parecen ser un empeño absurdo a la luz de su radical afirmación nihilista. Y más absurdo aún parece el propósito que por las mismas fechas (1960-61) le ocupa: la redacción de un curso de iniciación a la filosofía "para uso de una mecanógrafa y de otros lectores de su mismo género" que prevé emitir en 24 sesiones radiofónicas de un cuarto de hora ${ }^{4}$. Si no queremos quedarnos con la fácil respuesta de que su "práctica" contradice su "teoría", contradicción salvable, por otra parte, por su concepción dela primacía de los "motivos" de la razón práctica sobre las razones de la razón teórica, por ese último fondo irracional que según él está a la base de las opciones vitales profundas, cabe preguntarse: ¿qué quiere decir Gaos con que su filosofía conlleva que la enseñanza de la filosofía es tarea absurda?, ¿qué tensión sino antinomia revela entre el Gaos filósofo y el Gaos profesor de filosofía?, ¿no es más que una manifestación más del problema o aporía de la historicidad de la filosofía que, vivida en carne propia, constituye el tema de su Filosofía de la filosofía?

La afirmación surge de la concepción expuesta por Gaos de la subjetividad y momentaneidad de la validez de toda filosofía, de ser ésta siempre la perspectiva de un sujeto en un momento determinado cuya comprensión por el otro sólo es posible en la medida que se identifique con él. Dada la imposibilidad de la identificación total entre dos sujetos - y de un sujeto consigo mismo a lo largo del tiempo - la comprensión total de una filosofía ajena y su repetición o perdurabilidad como verdad - incluso para su autor mientras viva

3 "Sus discípulos sabemos que si en algo fue ejemplar la vida de Gaos, fue justo en su labor como profesor", Vera Yamuni: José Gaos, el Hombre y su Pensamiento, México, UNAM, 1980, p. 116.

+ Con humor, teniendo en cuenta las destinatarias, subtitulado en latín: Ad usum mecanographae aliorumque ejusdem generis lectorum. La serie nunca se emitió y el programa y los textos preparatorios, retomados y reelaborados el 1965 coincidiendo con la redacción del Del hombre, se encuentran en el vol. XVI de las Obras Completas, La filosofia en la universidad, México, UNAM, 2000, pp. 375 y ss. 
- es radicalmente imposible. Ahora bien, ¿de ello se concluye el absurdo de la enseñanza de LA filosofía? ¿No será, más bien, la conclusión correcta que es absurdo que el filósofo pretenda hacer del discípulo - pues de enseñanza se trata- una copia de sí mismo o, lo que es lo mismo, que acepte como su verdad la verdad del maestro? $Y$, en este último caso, ¿invalida ello la enseñanza de la filosofía o sólo la orienta hacia otra finalidad que la repetición imposible? La diferencia entre las dos conclusiones y sus consecuencias la ejemplifica la obra del propio Gaos. Si la primera se encuentra, como hemos visto, en su De la Filosofía, la segunda se encuentra en sus anteriores Confesiones profesionales (1953), y es una diferencia que no se explica por cambios en la concepción subjetiva y momentánea de toda filosofía y de su verdad como verdad histórica y personal, pues ambas obras la comparten. Si las obras filosóficas, para Gaos, son "situaciones" integradas por autores, los filósofos, y los destinatarios, discípulos y público, situaciones históricas por tanto ${ }^{5}$, la distinción entre las dos situaciones que representan las dos obras citadas puede albergar la diferencia, y precisar aquellas puede aclarar ésta.

Las Confesiones se inician advirtiendo que son Profesionales y no Filosóficas "porque - dice Gaos - estoy muy seguro de ser profesor de filosofía, pero lo estoy muy poco de ser filósofo. Para ser un filósofo parece que me falta - pues, caramba, nada menos que precisamente una filosofía" ${ }^{\prime}$. No es que no tenga ideas filosóficas propias, es que - y con ello parece hacerse eco de reproches de otros - no las ha desarrollado "en la forma al parecer la requerida de una verdad filosofica: sistemática, objetiva". Pretende ahora exponer esas ideas y cómo y por qué ha llegado a tenerlas. Son pues las confesiones profesionales del profesor las que expresarán sus ideas filosoficas. $Y$ la primera idea que expone es, precisamente, el carácter de verdad personal de cada filosofía y cómo la imposible identificación de los sujetos - las individualidades son reales, absolutas- impide, en rigor, su comprensión integral por parte de cualquier otro, lo que en su

5 De la Filosofia, op. cit., p. 406.

6 José Gaos: Confesiones Profesionales, Obras Completas, vol XVII, México, UNAM, 1982, p. 45. 
caso impide que quienes le escuchan puedan comprender y compartir totalmente su filosofía. Pero, sigue diciendo, "la Filosofía de la que acabo de hablar no es toda la Filosofía (...) no todo es tan personal, tan incomunicable" 7 . No nos interesa ahora qué parte considera que es la comunicable, sino la seguridad con que se afirma como profesor y el propósito de manifestar la filosofía que se le reclama como "confesiones de un profesor", por un lado y, por otro, las consecuencias para su práctica de enseñar filosofía del reconocimiento de un resto absolutamente incomunicable en toda filosofía.

No siempre consideró esencial su vocación de profesor. Como cuenta en las Confesiones, el problema vocacional se le planteó muy pronto, antes de instalarse como profesor en Madrid, en la forma de la pregunta "¿por qué me he decidido a hacer de la Filosofía, aunque sea por el rodeo de la enseñanza de ella, si es que es rodeo, mi profesión?"8. La duda sobre la posible separación entre las dos vocaciones - filósofo, profesor - que expresa el "si es que es un rodeo" parece más propia del momento de las Confesiones que del momento en que se cuestionó su vocación. En un artículo del 28 Abril 1937 escrito en París para la la revista Madrid, que le había pedido que reseñase su actividad intelectual, dice:

"No sé con toda seguridad cuál puedo tener por mi actividad propia. Iba a escribir que mi actividad docente. Pero me detiene mi consideración de que mi actividad docente no es mi única actividad, ni entre mis actividades la más propia sin duda alguna". ${ }^{\prime}$

Entre ésta y sus otras actividades de "estudio y reflexión", "traducción" y "pedagógico-administrativa", decide que "miactividad propia es la de estudio y reflexión que es fundamento de mi actividad docente". No es hasta 1939 con la aceptación de México como su destino cuando coinciden su proyecto de desarrollar el problema de

7 Idem, p. 48.

8 Idem, p. 109.

9 El texto del artículo en Vera Yamuni: José Gaos, el Hombre y su Pensamiento, op. cit. pp. 28-30. 
la Filosofía misma en una Filosofía de la filosofía, el convencimiento de que la base para ello se encontraba en la historia de la filosofía y la oportunidad que le ofrece ser acogido como profesor por la Facultad mexicana cuya generosidad le permite programar para sucesivos cursos un recorrido desde la filosofía griega hasta la contemporánea. Cuando había identificado la historicidad como el problema de la filosofía de su tiempo y el suyo propio por la experiencia biográfica que tras sucesivas verdades creídas le abocaban al escepticismo, se aplica a la enseñanza de la historia de la filosofía como parte integrante de la elaboración de su Filosofía de la filosofía. El proyecto como filósofo y como enseñante coinciden y en el 1953, cuando escribe las Confesiones, ha llegado hasta Hegel. Pero si no ha terminado el recorrido, en el camino ha conseguido otra cosa: tres generaciones ya de discípulos que le afirman como profesor y, ésta es la cuestión, ¿también como filósofo... aunque no tenga una obra que de forma sistemática exponga su filosofía? Es esta una tarea cuya necesidad se cuestiona: “Es un deber? ¿Está nadie obligado realmente a hacer una obra (...)? $¿$ No hay algo de servil, de cristiano, de protestante, de proletario en la conciencia obligatoria de la operosidad?" $10 \mathrm{El}$ problema es que no tiene "más remedio que confesar mi naturaleza proletaria, servil, cristiana, si no específicamente protestante", por lo que le desazona "perder el tiempo" y su demora en el historicismo sin "acabar" un sistema no puede explicarse sólo por el esteticismo y el hedonismo de complacerse en la lectura y en la reflexión que podrían responder al solo "afan de saber" que tradicionalmente se sitúa al orígen de la vocación filosófica. Hay otras causas en la demora cuya identificación requiere reconocer otros motivos para el filosofar.

En cambio, los discípulos atestiguan su condición de profesor. La relación maestro y discípulo que ha practicado ha dado sus frutos, tres generaciones distintas para las que pronostica destinos diver$\operatorname{sos}^{11}$. Para el modelo de escuela que practica - pues considera que la escuela es el modelo por excelencia de la enseñanza de la filosofía

${ }^{10}$ Confesiones Profesionales, op. cit., p. 111.

11 Generaciones que denomina de "historiadores", "hiperiones" y "hegelianos". 
- , construido sobre el recuerdo de su paso por la escuela de Madrid y con la analogía de fondo de la relación padre-hijo, esta diversidad en los resultados, el hecho de que ningún discípulo comparta la totalidad de las ideas del maestro y que todos difieran de él, es muestra de su éxito. En su doble propósito como profesor de informar y formar en la clase y en el seminario respectivamente, y más allá de ello en la relación personal, de amistad y convivencia informal con los discípulos, el respeto por la individualidad de estos se pone a prueba en un momento crucial de la relación que exige del profesor "una actitud y una conducta que tocan a los fondos más radicales de la personalidad". Se trata del momento de la emancipación de los discípulos, para el cual, si es "menester", el profesor debe dar "el empujón decisivo para que echen a volar por sus propias alas y por su propia cuenta y riesgo" y aceptar con serenidad y generosidad su necesaria rebeldía de independencia contra el maestro a quien se critica y se quiere superar por "anticuado e inepto" y a quien, de hecho, algunos superan ${ }^{12}$. Es el momento que reclama la humanidad y generosidad del "padre espiritual", condición necesaria para ser "auténtico y efectivo maestro". La enseñanza de la filosofía produce, inevitable, a "otros" distintos del maestro y en ello hay que complacerse. Y no sólo produce a otros, también el propio maestro es producido en la relación: "sea lo que yo sea, no lo sería, si mis discípulos no fuesen lo que son"13. Su reconocimiento de los discípulos "emancipados" es tal que, al inicio de la lectura de sus confesiones, sugiere - sólo sugiere - a los allí presentes la posibilidad de que fuesen recíprocas para enriquecerse todos con las confesiones de cada cual. Más aún, con ellos ha sentido "la experiencia quizá capital en la del tiempo de la vida, al menos según la mía y para mí", porque al pasarle delante los que venían detrás,

"entre el empezar a ser profesor, sin dejar de ser discípulo, y el seguir siendo profesor, empezando a ver a los discípulos empezar a ser

${ }^{12}$ Idem, p. 97.

${ }^{13}$ Idem, p. 99. 
profesores, llegar a ser maestros - hace la experiencia radical del tiempo, de la existencia, el que un día se oyó llamado a existirla en el modo de profesor". ${ }^{14}$

Los discípulos han devenido otros maestros. Distintos y algunos superiores. Es, lo reconoce, la primera "ráfaga emisaria de la vejez".

No hay duda de que en esta posición de plenitud de profesor encaja mal la conclusión nihilista sobre la enseñanza de la filosofía. Quien ha hecho en la historia de la filosofía - saber transmitido por tanto - la experiencia que determina su problema filosófico propio, quien ha hecho de su estudio y enseñanza a la vez su camino para resolver su problema y su modo de existencia en el tiempo, quien busca y logra como "formador" reafirmar la diferencia del otro ¿puede considerar absurda la enseñanza de la filosofía? Al contrario, hay un optimismo pedagógico que se manifiesta en sus abundantes escritos de la década de los cincuenta relativos a la enseñanza de la filosofía en la universidad que ofrecen un conjunto preciso y extenso de propuestas didácticas y organizativas ${ }^{15}$. No puedo entrar ahora en su detalle, pero reseñar sus líneas maestras mostrará cómo traducen su autoconcepción como profesor expresada en las Confesiones. Se trata como finalidad última de enseñar a investigar, a inventar, a crear, a trabajar personal y originalmente, por ello lo importante y decisivo son los métodos de enseñanza y no los planes estando supeditados éstos a aquellos, porque no importa tanto el qué o el cuánto de la información sino cómo se aprende - más vale poco pero bien-, y la mejor forma de aprender es trabajando con quien ya sabe porque no se enseña sólo filosofía sino a filosofar y ello requiere iniciar a los estudiantes en el filosofar con los grandes filósofos y con los profesores. A ese propósito responde la centralidad del comentario de texto en la clase, la imprescindible lectura profunda y minuciosa de al menos dos obras cumbre de la historia de la filosofía y la lectura de

14 Ibidem.

${ }^{15}$ Ahora recogidos en el vol. XVI de las Obras Completas, La filosofia en la universidad, op. cit. 
las biografías de los filósofos para verles "como hombres de carne y hueso, y como héroes del trabajo intelectual"16; y el mismo propósito justifica la importancia capital de los diversos tipos de seminarios que distingue y reglamenta como forma idónea de trabajar juntos, de cofilosofar, los alumnos con el profesor y ambos con los grandes filósofos, y la necesidad también de una buena formación de profesores con su correspondiente didáctica de la filosofía, profesores que si no están seguros de tener una filosofía propia han de atenerse a ser intermediarios entre los alumnos y los textos. $Y$ es una enseñanza que será formativa si culmina en el "diálogo articulador de la convivencia de un tipo de comunidad como la de las escuelas en el sentido más clásico de este término" y que ha de conducir al discípulo "hasta poder prescindir del maestro, e incluso renegar de él, rectificándolo, superándolo, innovando" ${ }^{\prime 17}$. No hay otro camino o método.

Son textos que hacen cuerpo con las Confesiones y con las que es coherente la "Advertencia" que escribe para la edición en 1956 de algunos de ellos como libro titulado precisamente La filosofía en la universidad:

"este librito de apariencia un tanto insignificante, pudiera ser la publicación más significativa del autor. Éste es, esencialmente, un profesor, y éste, a su vez, se confiesa, como en ninguna otra de sus publicaciones, en este librito" ${ }^{18}$

Su optimismo pedagógico, sin embargo, no pierde su punto de escepticismo o cautela sobre el lugar y papel de la filosofía en su tiempo, y en un breve pero denso escrito de 1951 que inicia el libro se plantea si la pretensión de restauración de la filosofía que observa en esos años no será una reacción contra la modernidad, si la filosofía no es ya una forma arcaica restaurable sólo por reacción. Pero aún en

${ }^{16}$ Idem, p. 99.

${ }^{17}$ Idem, pp. 64-65.

${ }^{18}$ Idem, p. 47. 
este caso, que haría de la enseñanza de la filosofía para formar profesionales de ella si no una actividad absurda, sí una actividad reaccionaria y condenada a la obsolescencia, aún así esta enseñanza no perdería un valor educativo fundamental que extiende su interés más allá de los "vocados" a ella:

"El conocimiento de las discrepancias de los filósofos, en las que, (...) se revela con transparencia superlativa la multiforme pluralidad de las culturas y hasta de los individuos con su singularidad irreducible, absoluta, que hace la riqueza, espléndido espectáculo, de la realidad (...) bien pudiera ser el método por excelencia de la formación de espíritus que, en vez de reaccionar ante lo que advierten disidente de ellos mismos con ciega acometida de animal fiero, sean capaces de complacerse en el paisaje de las infinitas singularidades hasta el punto de cooperar a fomentarlo con una acción que supere el esteticismo". ${ }^{19}$

Finalmente, es la transmisión del conocimiento, respeto y fomento de la diversidad lo que salva la enseñanza de la filosofía y, con ella, a su profesor.

Pero el profesor - y volvemos a las Confesiones - sólo logra discípulos y es maestro si siente entusiasmo por su profesión, si vive la posesión por la actividad de su vocación "como deidad o numen divino o demoníaco", pues esto es lo que de verdad es contagioso y formativo. Y más al fondo aún de la pasión y el entusiasmo, más allá de la apariencia "paternal y divinal" de la vocación pedagógica, cabe la sospecha que apunta de que no sea más que

"una hipócrita versión, en el fondo, en la raíz, de la voluntad de poder - y de la voluntad de poder del débil y cobarde - que no atreviéndose a dar la cara, echa por el rodeo de la idea y de la mayéutica de ésta...". 20

\footnotetext{
${ }^{19}$ Idem, p. 50.

${ }^{20}$ Confesiones Profesionales, op. cit., p. 100.
} 
Es esta posible profunda raíz psicológica la que une también al maestro y al filósofo. Como es sabido Gaos, desde muy pronto, piensa que la esencia de la filosofía es la soberbia, que su motivo más profundo no proviene del lado del placer sino del del poder, si acaso con placeres satánicos; que procede, dice, de la conciencia de superioridad intelectual superlativa y de la voluntad de dominio sobre todo con el dominio del principio de todo, es decir, del pretender superponer sobre Dios la propia inteligencia y por ello es "el esencial destino de la Filosofía el idealismo trascendental", y, también por ello, al hacerse cargo de la propia situación, experimenta la radical vivencia de su esencial ser luciferino, demoníaco, pues cada filósofo repite "el pecado de Satán y la caída - la caída de la comunidad, de la comunión en la fe, en el abismo solitario del Sí mismo, no sin fondo, sino cuyo fondo es el mismo Sí mismo..." con el inevitable horror sacrílego del solus ipse ${ }^{21}$. En las Confesiones analiza su propia soberbia, su modo de ser filósofo, pero más en particular expone su vivir la soledad que conlleva y la repercusión de todo ello en su obra, sobre todo en la "demora" en hacer la obra "acabada" que reclama el deber de la "operosidad". Se pregunta si está en las vivencias de su infancia de "nieto único" el origen de haber vivido la vida como soledad del individuo y de haberse hecho las ideas que tiene "acerca de la individualidad como forma categorial de la realidad universal y de la Filosofía como forma de expresión de la individualidad"22, pero, en cualquier caso, es el horror de ser individuo el que le ha llevado a ensayar todas las huidas posibles para no vivir ese horror. Son algunas de estas huidas y su fracaso final las que ahora nos interesan.

Precisamente es la huida que llama "pedagógica", el hacer profesión de la educación (sea ello por eros pedagógico o por voluntad de poder de un ser incapacitado para ejercerlo donde es propio, en la política), es la relación educativa que es psíquica e íntima con otros seres humanos y que requiere comunicatividad afectiva e intelectual,

${ }^{21}$ Idem, p. 119.

${ }^{22}$ Idem, p. 121. 
este caso, que haría de la enseñanza de la filosofía para formar profesionales de ella si no una actividad absurda, sí una actividad reaccionaria y condenada a la obsolescencia, aún así esta enseñanza no perdería un valor educativo fundamental que extiende su interés más allá de los "vocados" a ella:

“El conocimiento de las discrepancias de los filósofos, en las que, (...) se revela con transparencia superlativa la multiforme pluralidad de las culturas y hasta de los individuos con su singularidad irreducible, absoluta, que hace la riqueza, espléndido espectáculo, de la realidad (...) bien pudiera ser el método por excelencia de la formación de espiritus que, en vez de reaccionar ante lo que advierten disidente de ellos mismos con ciega acometida de animal fiero, sean capaces de complacerse en el paisaje de las infinitas singularidades hasta el punto de cooperar a fomentarlo con una acción que supere el esteticismo". ${ }^{19}$

Finalmente, es la transmisión del conocimiento, respeto y fomento de la diversidad lo que salva la enseñanza de la filosofía y, con ella, a su profesor.

Pero el profesor - y volvemos a las Confesiones - sólo logra discípulos y es maestro si siente entusiasmo por su profesión, si vive la posesión por la actividad de su vocación "como deidad o numen divino o demoníaco", pues esto es lo que de verdad es contagioso y formativo. Y más al fondo aún de la pasión y el entusiasmo, más allá de la apariencia "paternal y divinal" de la vocación pedagógica, cabe la sospecha que apunta de que no sea más que

"una hipócrita versión, en el fondo, en la raíz, de la voluntad de poder - y de la voluntad de poder del débil y cobarde - que no atreviéndose a dar la cara, echa por el rodeo de la idea y de la mayéutica de ésta...". ${ }^{20}$

\footnotetext{
${ }^{19}$ Idem, p. 50.

${ }^{20}$ Confesiones Profesionales, op. cit., p. 100.
} 
Es esta posible profunda raíz psicológica la que une también al maestro y al filósofo. Como es sabido Gaos, desde muy pronto, piensa que la esencia de la filosofía es la soberbia, que su motivo más profundo no proviene del lado del placer sino del del poder, si acaso con placeres satánicos; que procede, dice, de la conciencia de superioridad intelectual superlativa y de la voluntad de dominio sobre todo con el dominio del principio de todo, es decir, del pretender superponer sobre Dios la propia inteligencia y por ello es "el esencial destino de la Filosofía el idealismo trascendental", y, también por ello, al hacerse cargo de la propia situación, experimenta la radical vivencia de su esencial ser luciferino, demoníaco, pues cada filósofo repite "el pecado de Satán y la caída - la caída de la comunidad, de la comunión en la fe, en el abismo solitario del Sí mismo, no sin fondo, sino cuyo fondo es el mismo Sí mismo..." con el inevitable horror sacrílego del solus ipse ${ }^{21}$. En las Confesiones analiza su propia soberbia, su modo de ser filósofo, pero más en particular expone su vivir la soledad que conlleva y la repercusión de todo ello en su obra, sobre todo en la "demora" en hacer la obra "acabada" que reclama el deber de la "operosidad". Se pregunta si está en las vivencias de su infancia de "nieto único" el origen de haber vivido la vida como soledad del individuo y de haberse hecho las ideas que tiene "acerca de la individualidad como forma categorial de la realidad universal y de la Filosofía como forma de expresión de la individualidad" 22 , pero, en cualquier caso, es el horror de ser individuo el que le ha llevado a ensayar todas las huidas posibles para no vivir ese horror. Son algunas de estas huidas y su fracaso final las que ahora nos interesan.

Precisamente es la huida que llama "pedagógica", el hacer profesión de la educación (sea ello por eros pedagógico o por voluntad de poder de un ser incapacitado para ejercerlo donde es propio, en la política), es la relación educativa que es psíquica e íntima con otros seres humanos y que requiere comunicatividad afectiva e intelectual,

${ }^{21}$ Idem, p. 119.

${ }^{22}$ Idem, p. 121. 
la que más puede servir "para olvidarse de sí mismo y sentirse mejor". De hecho, confiesa, "la única situación de la vida en que estoy prácticamente siempre de buen humor, es la clase" ${ }^{23}$. Sin embargo, no es esta la huida importante, sino la que en su opinión se esconde en la atribución de la universalidad a la verdad como rechazo de la verdad "histórica", "personal", por la angustia y el horror que produce asumir la responsabilidad absolutamente singular que supone esta última y que no se puede compartir con nadie. Es, quizás, esta huida hacia la verdad universal el ápice de la Filosofía, de la soberbia, pues ¿quién menos solitario, menos individuo que quien es sujeto del cual son atributos las demás cosas? Pero ni aún así, no hay forma de aniquilar sin residuo la soledad, la individuación; la experiencia de la soledad intelectual, mental, espiritual es esencial y forzosa en el filósofo porque es "la experiencia de no convencer nunca del todo a todos los demás, del no ser comprendido del todo por nadie..." y ello porque la objeción radical del otro es precisamente que es otro, distinto y disidente, y sería insensato "desear que no sea él sino yo" ${ }^{\prime 24}$.

Sin embargo, hay modos de soledad más terribles aún "por aislar más del sujeto de más del resto entero del universo" y son la soledad "histórica" y, sobre todo, la que llama "actual", la que evidencia los cambios de puntos de vista que ha experimentado a lo largo de su evolución intelectual y que añaden a la subjetividad de toda filosofía la "momentaneidad", el ser cada momento una "singularidad puntualidad de vista" que aisla su yo en la realidad peculiar de lo actual, en su actualidad que cancela la anterior y que sabe será cancelada en el futuro ${ }^{25}$. Y pese a toda convivencia y comunicación que sin duda hay, nada reduce a nada la soledad. Ni siquiera puede la soberbia filosófica del dominio de todo, porque con la ironía y el humor ("el arte de proteger lo que más entrañablemente se siente" ${ }^{26}$ )

\footnotetext{
${ }^{23}$ Idem, p.122.

${ }^{24}$ Idem, pp. 124-125.

${ }^{25}$ Idem, p. 127, en cursiva en el original.

${ }^{26}$ Idem, p. 100 .
} 
del delicioso relato final de su viaje en los autobuses mexicanos mientras lee en alemán un texto de la Crítica de la Razón Pura muestra, recurriendo a una expresión de Ortega, que esa soberbia no es más que un "error de perspectiva humillado, esto es refutado existencialmente por la soledad o individuación ${ }^{\prime 27}$. La individualidad es un misterio, el misterio del ser.

$Y$ llegan entonces las preguntas finales con las que responde a la duda inicial de si tiene o no una filosofía propia: la relación que acaba de exponer de sus ideas y sus circunstancias ¿son o no filosóficas? ¿Es o no "sistemática" y congruente con su sentido la forma de expresión adoptada, es decir, las confesiones del profesor de filosofía? Más aún: "¿Será congruente con su sentido el comunicarlas ni siquiera de esta forma?" Son preguntas sin respuesta que abandona en la reclusión poética machadiana de sus soledades y sus pensamientos, en la aceptación final como filósofo de la irreductible soledad, de la insalvable individualidad, de su imposible comunicación total ${ }^{28}$. No afecta ello sin embargo a su tarea como profesor. En la madurez en que se encuentra, la primera ráfaga de la vejez que le ha sacudido al verse superado por discípulos y que, con bella metáfora, observa que ha dejado a sus pies "unas hojas de la cima de su copa", es acogida con el propósito de "vigorizar con ella las frondaciones postreras" ${ }^{29}$.

La "situación" de las Confesiones es, pues, la del profesor seguro de su profesión y la del filósofo de la Filosofía de la filosofía, de la historicidad de la filosofía, que ha expresado ante sus discípulos lo comunicable de ella en la forma de confesiones de profesor que muestran la historicidad del propio sujeto que las formula y la precisa actualidad en que las formula, esa actualidad que precisamente evidencia lo irreductible e incomunicable de la individualidad que es él mismo. Considera su propia biografía, en la forma en que la ha narrado, la máxima expresión posible de su filosofía más propia que,

${ }^{27}$ Idem, p.137.

28 "En fin," termina, "A mis soledades voy/.../ ...para andar conmigo/ me bastan mis pensamientos".

${ }^{29}$ Idem, p. 99. 
sin embargo, en su sentido más profundo cuestiona la posibilidad misma de su expresión. Es, también, una situación abierta al futuro, seguirá formando discípulos, seguirá en su soledad andando consigo mismo y sus pensamientos. Inevitablemente seguirán otros "momentos" con sus propios puntos de vista. Y es este aspecto justamente el que diferencia con más radicalidad esta situación de la situación que representa el De la Filosofia, obra marcada por la probable muerte inminente que le anunció el ataque al corazón de 1958.

Si sólo la muerte puede detener los sucesivos momentos de la subjetividad del filósofo, el fluir y sucederse de descubrimientos y ocurrencias y el continuo articularlas y rearticularlas que le ocupa, únicamente quien siente o sabe con fundamento de su inminencia puede pensar que su concreta articulación de ese momento será la definitiva para él, y puede pensar que es urgente fijarla por escrito

"si le interesa la posibilidad de que alguien que le sobreviva siga rearticulándolas, o simplemente dejar constancia documental de haber pasado la vida esforzándose por descubrir, por que se le ocurriera; y por articular y rearticular aquello que, al hacer profesión, contrajo el deber de esforzarse por descubrir, por que se le ocurriera y por articular y rearticular". ${ }^{30}$

Esta es la circunstancia concreta de Gaos que le mueve a escribir De la filosofia y que hace explícita a su inicio. Su momento es como si su vida fuera a acabar al poner punto final al curso, como recuerda al llegar a ese punto. No caben más demoras para realizar la obra acabada y sistemática de su filosofía cuyo cumplimiento le exigía su sentido proletario y protestante de la operosidad y al que se resistía y creyó cumplido en sus confesiones de profesor. Cuando puede llegar a su fin el monólogo en soledad de su filosofía más íntima e incomunicable, el Gaos vocado a la filosofía, poseído por la soberbia filosófica y el afán de dominación, que se sabe solo y solitario en su

${ }^{30}$ De la Filosofia, op. cit., p. 8 
punto de vista quiere, como mínimo, dejar constancia textual que ha cumplido con su deber profesional de filósofo. No vale ya para ello la biografía del profesor, de éste sólo le vale la forma de expresión, el curso con sus lecciones, pero el contenido es estrictamente filosófico: su Filosofía de la filosofía, el resultado en filosofemas de su continuo bregar con lo que consideró EL problema de la filosofía, su historicidad, y sobre el que actuó su soberbia filosófica. Es el Gaos filósofo quien habla. La exposición sistemática principia - y lo remarca - en $s u$ situación (subjetividad) en la primera clase (momentaneidad) y el sucederse de las lecciones le llevará desde la fenomenología de la expresión verbal hasta una antropología filosófica, "la consistente en dar razón recíprocamente del hombre por la Filosofía y de la Filosofía por el hombre" 31 . Pero el filósofo de la Filosofía de la filosofía ha de dar cuenta también de quién es el sujeto que filosofa, el profesional de la filosofía, y de en qué consiste la historia de la filosofía, la tradición en la que se inscribe y cuya consistencia problemática movió su filosofar. Son la antepenútima y penúltima lecciones del curso.

De su descripción del filósofo, el "entusiasta" o el "endiosado" que por su soberbia semejante a la de Lucifer resulta la encarnación más cabal del Demonio mismo, que como hombre de escuela, de gabinete, de recinto y encierro herméticos y sistemáticos pretende ejercer la dominación intelectual por medio de las ideas, y que como solitario aislado en las alturas paga el precio del solipsismo, nos interesa ahora las consideraciones sobre los destinatarios de su palabra. Son los "iniciados" y el "público", este último "la Humanidad contemporánea y futura toda" ${ }^{\prime 2}$. Los iniciados, en la antigua Grecia como ahora "los admitidos a las enseñanzas privadas de un Heidegger", consiguen entender la terminología y fraseología del maestro y por el "entusiasmillo" y el "endiosamientecillo" que logran se convierten en acólitos propagandistas de la filosofía del escolarca que, por medio de ellos, se dirige al público en general. Descartes rompe el modelo

\footnotetext{
${ }^{31}$ Idem, p. 5, en cursiva en el original.

${ }^{32}$ De la Filosofia, op. cit., p. 404.
} 
al dirigirse directamente al público sin discípulos de intermediarios. Sea a través de discípulos o directamente, una distinción emerge como relevante entre los destinatarios de la filosofía: son muchos los que se acercan a ella por diversos motivos o intereses, pero muy pocos, poquísimos, los "destinados" a ella ${ }^{33}$. El "vocado", el "destinado" a la filosofía es "únicamente el condenado por Dios a ser demonio filosófico por dotado a nativitate de la psicología" que Gaos ha descubierto como la propia del filósofo. Una conclusión se impone aunque Gaos no la explicita: el filósofo se hace, sí, porque debe adquirir métodos, prácticas, hábitos profesionales, pero no se hace si previamente no nace. Los lectores de filosofía viven sólo de forma vicaria la experiencia de la pasión filosófica que el autor vivió originaria y creadoramente, pero sólo el vocado, al reconocerse en ella y "con-sentirla", como le pasó a Gaos en su lectura adolescente de la Historia de la filosofia de J. Balmes, puede sentirse impelido a hacer de ella profesión de vida.

De la historia de la filosofía, la penúltima lección, de la unidad y pluralidad que descubre en ella, interesa ahora sólo la imposibilidad de su acabamiento, su carácter inevitablemente abierto y las dos principales razones de ello. Las filosofías son tantas como filósofos y si bien las posiciones antinómicas y las concepciones sustancialistas o antisustancialistas posibles son en número limitado (uno de los aspectos que da unidad a la historia de la filosofía), las posibles combinaciones entre ellas y con conceptos subordinados son prácticamente ilimitadas, por lo que "hay todavía una posible filosofía para cada filósofo futuro" ${ }^{34}$. Que puedan haber filosofías originales (por ejemplo, recuerda, una filosofia nacional, por caso mexicana) es pues consus-

${ }^{33}$ Ya en 1939 publicó en La Habana el texto Sobre el auditorio de filosofia (ahora en el vol. VII de las Obras Completas, Filosofia de la filosofia e historia de la filosofía, México, UNAM, 1987, pp. 71-99) donde distinguía a "los forzados de la filosofía", "los snobs", "los afanosos de la cultura", "los afanosos de la expresión", "los afanosos de hacerse valer, superioridad y poder o dominación", "los afanosos de liberación", "los afanosos de las reglas", ninguno de los cuales se acercaba a la filosofía "por ella misma", razón que sólo movía al, en singular, "vocado".

${ }^{34}$ De la Filosofia, op. cit., p. 415. 
tancial a la propia historia de la filosofía. La segunda razón es externa a ella, es el factor de irracionalidad que representa la incapacidad de la inteligencia humana, aún la más capacitada del genio, para sistematizar todos los ingredientes que se quieren componer en un sistema filosófico: el rompecabezas que pretende el gran filósofo es tan complicado que no puede ajustar unas piezas sin desajustar otras.

Finalmente, una Filosofía de la filosofía, como lo es la expuesta en el curso, como teoría de la filosofía, debe dar cuenta también de sí misma y no sólo en los términos generales que ella misma contiene. Exige más, también se "ha de traducir a forma explícita en terminos individuales" ${ }^{\prime 35}$. Requiere una autobiografía de su autor, José Gaos, que se aplique a sí mismo las ideas expuestas sobre la historia de la filosofía, y una autocrítica que se aplique a sí las ideas sobre la subjetividad y momentaneidad de la filosofía, y en particular la ahora expuesta del rompecabezas. Son los temas de la última lección a cuyo final encontramos el problema origen de este escrito. La parte autobiográfica remite como antecedente a las Confesiones, pero ahora se limita al Gaos filósofo por lo que se reduce a recordar cómo descubrió su vocación filosófica e hizo de ella profesión de vida, a señalar con minuciosidad los antecedentes biográficos de cada una de las ideas expuestas en el cuerpo del curso, su filiación en autores leídos y en circunstancias y reflexiones propias, así como a señalar también las abandonadas en el camino. Resaltaré sólo una de las que mantiene y una de las abandonadas. La primera la considera prácticamente propia y vinculada a su vocación filológica, que también le tentó, y se trata de "la idea de que la Filosofía de la Filosofía debía aprehender la Filosofía misma ante todo en su realidad más aprehensible perceptiblemente, menos discutible filosóficamente, la de los textos mismos $^{\prime 36}$. La segunda, la abandonada después de ocuparle mucho tiempo y trabajo, es "la idea de que la definición de la filosofía sería la síntesis suma de la Filosofía de la Filosofía" y ésta su despliegue más cabal, abandono que se produce cuando cae en la cuenta de que

${ }^{35}$ Idem, p. 416.

${ }^{36}$ Idem, p. 422. 
la subjetividad de la filosofía en general incluye la de su definición ${ }^{37}$. No hay escapatoria a la subjetividad en el metadiscurso sobre la subjetividad de toda filosofía.

La parte autocrítica señala las deficiencias de su sistema, los inevitables desajustes de su rompecabezas de los que ya es consciente y que, en número de 6 seguido por unos etcétera, etcétera, afectan a cuestiones sustantivas y centrales de su propuesta de combinación. Es la parte que concluye, al aplicar la subjetividad y momentaneidad de toda filosofía a la suya, con que no puede proponer el curso como válido para quienes lo han seguido ni para nadie. La Filosofía de la filosofía se revela al fin como "una teoría del tropo de Agripa, de la discrepancia de los filósofos: quien discrepe de ella la confirma; quien asintiere a ella la invalidaría" ${ }^{\prime 38}$. Sólo es válida para él y mientras el seguir viviendo no lo lleve a disentir de sí mismo.

Este es "el fondo último de la subjetividad y momentaneidad" por el que filosóficamente a fondo no puede haber más que monólogo en soledad y por el que se reduce al absurdo la enseñanza de la filosofía. Como he señalado anteriormente, Gaos ya estaba en posesión de esta concepción subjetiva y momentánea de la filosofía en las Confesiones que, hemos visto, concluyen con el profesor provocando y complaciéndose en la desidencia de sus discípulos y el filósofo recluyéndose en el monólogo en soledad. Ahora, en el De la filosofia, el filosofo, que cree inmediata su muerte y con ella el fin de su monólogo, al cumplir su deber de fijar por escrito el punto de vista alcanzado y constatar su no validez para otros, no ve remedio al absurdo de la enseñanza de la filosofía. El filosofo cuestiona la tarea del profesor, ¿por qué? La semi-retractación que efectúa, aquello pues que sí consentiría diálogo y enseñanza, nos ayudará a precisar más a qué absurdo se refiere. Desde otro punto de vista del de la subjetividad, se trata, en breve, del reconocimiento de que el curso es "un resultado y una síntesis biográficos de la historia contemporánea de la filosofía" que va de Husserl a Heidegger y que tiene acaso el

${ }^{37}$ Idem, p. 425.

38 Idem, p. 427. 
pequeño merecimiento de "haber procedido de la técnica de los fenomenólogos a lo patético y dramático de los nietzscheanos" lo que le permite designarlo, de forma emblemática, como rekantiano y renietzscheano ${ }^{39}$. Es su particular combinación del rompecabezas y su colocación en la historia de la filosofía, en el lugar que cree corresponde a su texto en la historia de textos que es para él la parte aprehensible de la filosofía. Si el profesor se salvaba con sus discípulos, el filósofo lo hace con sus textos propios. Sin embargo no le basta, porque con ello sólo se retracta a medias. Pero ¿no es en los textos mismos en donde el filósofo Gaos, como idea propia, cree encontrar la filosofía misma para hacer su filosofía de ella?, ¿no es en los textos donde el profesor Gaos fija la materia de las clases y seminarios que enseñan a filosofar? ¿por qué esto es tan sólo una hemipanilodia y cuál es, por tanto, el semi-absurdo que aún queda en la pretensión de enseñar la filosofía?

La razón ha de ser lo que queda fuera del texto o, mejor, lo inexpresable en texto, lo más profundo de la subjetividad, la irreductible individualidad del filósofo; sin embargo, si bien tiene razón en decir que es absurdo pretender enseñar lo caracterizado precisamente como intransmisible, ello sólo hace absurda la enseñanza de la filosofía en la medida que se le asigne a ésta la misión de objetivar del todo la singularidad del filósofo y transmitirla, pero en este caso lo absurdo sería probablemente asignarle esta misión y no el inevitable fracaso en cumplirla. Cierto es que en Gaos la subjetividad y momentaneidad de toda filosofía lleva a que sólo desde el punto de vista de su autor sea posible la comprensión completa y la aceptación total de su validez, y es por tanto tan inevitable la incomprensión y el desacuerdo del otro como imposible que ese otro sea idéntico al autor, pero, de nuevo, que ninguna filosofía concreta alcance validez total para el otro y que ninguna hermenéutica del texto lleve a la completa y particular comprensión que su autor tenía de él ¿hace absurda (o semi-absurda) la enseñanza de la filosofía? ¿No era la pluralidad filosófica la evidencia del espléndido espectáculo de la diversidad

${ }^{39}$ Idem, p. 428. 
individual y el valor profundo de la enseñanza de la filosofia? ¿no es imposible lograr la solución perfecta del rompecabezas del todo? ¿no era cada filosofía, en la comprensión que se lograra de ella, parte de un camino para hacer otra, la propia de cada cual en su circunstancia histórica y biográficamente en perpetuo cambio? ¿A quién puede importar tanto que se logre la comprensión y el acuerdo del otro a una filosofía, sin resquicios ni reservas, hasta el punto de considerar absurda, aunque sea parcialmente, una enseñanza que no lo logre? Creo que sólo a su autor, que sólo puede sentirse desazón ante el resto incomunicable de toda filosofía cuando coinciden en la misma persona el filósofo y el profesor, sólo cuando el profesor no pretende enseñar a filosofar sino enseñar su filosofía propia sabe del "resto" que queda. Sobre todo si ha hecho Filosofía de la filosofía y ha encontrado la principal razón de la filosofía en las profundidades psicológicas, en las mociones y emociones del sujeto y su dual condición moral cuyas contradicciones se resuelven por las "razones del corazón" y, en consecuencia, considera la filosofía como forma de expresión de la individualidad hasta ese fondo. Es él entonces el único capaz de reconocer la diferencia - y el acuerdo - entre lo que es y las formas de expresión que ha ensayado para revelarse, para mostrarse.

Tanto esfuerzo, la vida toda, para hacer su propio rompecabezas y al final sabe que la comprensión total de éste desaparecerá con su muerte y que su destino será, en el mejor de los casos, ser descompuesto $y$, tal vez, algunos de sus elementos ser utilizados en nuevas recomposiciones por alguien que, además, si se pone a ello, será por su destino demoníaco de la soberbia filosófica que, obviamente, no se puede enseñar. Sería el absurdo del saberse Sísifo, la condena al fracaso, que el propio Gaos documenta, de la soberbia filosófica que pretendía dominarlo todo. Pero no sólo ello en el caso de Gaos, aunque la conversión del fracaso en el fondo de transmitir $S U$ filosofía en el fracaso de transmitir $L A$ filosofía revele su soberbia, no por analizada menos operante, no por ser considerada "un error de perspectiva" ausentede su perspectiva. Probablemente este fracaso para Gaos, más que consecuencia y expresión de la condición de verdad histórica y personal de la Filosofía de la filosofía que pretendía 
dar razón de la verdad histórica y personal de toda filosofía, es consecuencia y expresión de la, finalmente, insalvable soledad de su irreductible individualidad, del aislamiento de su singularidad que crece en su afirmarse y autoconocerse y en el fondo no admite puentes. Definitivamente, el problema de la soledad profunda del individuo, en el fondo, no tiene remedio. Nadie le puede comprender del todo, está solo en su aquí y ahora que constituyen su yo y su mundo y nadie puede ponerse en su lugar. Pero, ¿es esto privativo de José Gaos?, ¿es saberlo privativo del filósofo?, ¿merece por ello considerarse absurda la enseñanza de la filosofía?, ¿es que es ese resto inefable, en su singularidad irrepetible, lo que en "el fondo" la justifica?

La probabilidad de la muerte, fin de la finitud del hombre, la solemnidad de la escritura de un texto que la muerte convertiría en expresión definitiva y última de su vida filosófica, su lectura a un público de sólo cinco alumnos oficiales que siguieron de principio a fin el curso ${ }^{40}$, sin duda acentuó su aspecto patético y dramático, su característica renietzscheana, y también su fondo religioso pues, ¿no hay algo del cristiano en el deseo, pese a saberlo irrealizable, de que perdure su yo más íntimo, de salvar su individualidad que en el fondo de sí misma y en lo no compartida por nadie es, él mismo lo dice, quizá nada, quizá la nada? ${ }^{41}$

No importa, para la interpretación apuntada, que sepamos que Gaos no murió al poner punto final al curso y que a este texto siguieron otros y nueve años más de vida de su autor. No lo sabía Gaos y esa es pues la situación en que lo escribió. Sí importa, sin embargo, saber de sus textos posteriores y de sus años finales para conocer en ellos la repercusión de esta hondura o altura alcanzada por su pensamiento y su soledad en su concepción de la filosofía misma y su función social, de su enseñanza y su valor educativo, o, también, en sus últimas preocupaciones religiosas. Fueron los 60 del pasado siglo años difíciles, convulsos políticamente, que aún le depararían la experiencia dramática de su renuncia, por principios morales, a se-

\footnotetext{
40 A quienes se siente agradecido "por haber hecho con tal asistencia posible el curso mismo", ibidem, en cursiva en el original.

${ }^{41}$ Confesiones Profesionales, op. cit., pp. 124 y 128.
} 
guir ejerciendo como profesor en la universidad mexicana y que acabarían, según Vera Yamuni, con un Gaos que "como hombre, profesor y filósofo se alojaba rezagadamente en un rincón..." ${ }^{22}$ Son asuntos, sin embargo, que aunque ya he explorado en parte, habrá que dejar para la continuación futura de este escrito, es decir, para otro momento.

Data de Registro 06/12/05

Data de Aceite 16/01/06

${ }^{42}$ Vera Yamuni, op. cit. pp. 130-131. 